\title{
Nanochitin whisker enhances insecticidal activity of chemical pesticide for pest insect control and toxicity
}

Zhenya Li ${ }^{1,3}$, Hezhong Wang ${ }^{2,3^{*}} \mathbb{0}$, Shiheng $\mathrm{An}^{1}$ and Xinming Yin ${ }^{1^{*}}$

\begin{abstract}
Background: Nanomaterials in plant protection promise many benefits over conventional pesticide products. Nanoenabled pesticides may alter the functionality or risk profile of active ingredients. Cationic nanochitin whiskers (NC) possess strong biological activity against wheat aphids. However, toxicity and synergistic effects of NC with chemical pesticides against pest insects has not been systemically reported. This study investigated the insecticidal enhancement by NC with Omethoate (40\% EC), Imidacloprid (10\% WP), and Acetamiprid (40\% WG) for pest control using wheat aphid as piercing-sucking mouthparts insect. Fluorescein isothiocyanate labelled NC was used to monitor the uptake and transportation pathway of NC inside the target insects. Toxicity of NC was tested with Sprague-Dawley (SD) rat. Our findings provide a theoretical basis for future application of NC in plant protection against pest insects.

Results: NCs synthesized by acidic hydrolysis were rod-like nanoparticles in a range of 50-150 nm in length and 30-50 nm in width, which examined by electron microscopy and dynamic light scattering methods. The charge density and zeta potential were about $63 \mathrm{mmol} / \mathrm{kg}$ and $+36.4 \mathrm{mV}$, respectively. By absorption and/or contact action of $30-50 \mathrm{mg} / \mathrm{L}$ of $\mathrm{NC}$ suspension, the corrected mortality of wheat aphids reached up to $80 \%$ or above after $12 \mathrm{~h}$ treatment, NC could be distributed through digestive system and relocated from mouth to other tissues inside the insect body. When associated with dilutions of conventional pesticides, the corrected mortality were significantly increased up to $95 \%$ or above. The dosage of the chemical pesticide and nanochitin in the mixtures (1:1 by volume) were all reduced to half. The acute oral toxicity Lethal Dose $50 \%\left(\mathrm{LD}_{50}\right)$ to SD rat is greater than $5000 \mathrm{mg} / \mathrm{kg} \mathrm{BW}$ (body weight) in male and female, acute dermal toxicity $L_{50}$ is greater than $2000 \mathrm{mg} / \mathrm{kg}$ BW of NC.

Conclusions: NC has a strong promotive effect on insecticidal effectiveness of chemical insecticides. It was easily absorbed by plant, transported and distributed from mouth to other tissues of the insects while sucking plant fluid. Low acute oral and dermal toxicity to SD rat indicated that it is safe to apply in agriculture and food industry. NCs has a great potential for water-based nanopesticide formulation to reduce chemical pesticide use for future agro-environmental sustainability.
\end{abstract}

Keywords: Nanochitin whisker, Insecticidal activity, Synergy, Mortality, Wheat aphids, Toxicity

*Correspondence: hezhongw@126.com; xmyin@henau.edu.cn 1 Department of Entomology, College of Plant Protection, Henan Agricultural University, 450002 Zhengzhou, China

${ }^{3}$ Department of Pesticide Science/Nano Agro Center, College of Plant Protection, Henan Agricultural University, 450002 Zhengzhou, China

Full list of author information is available at the end of the article

\section{Introduction}

As a recognized cutting edge technology, nanotechnology has been applied across a wide range of areas, perhaps more recently in the natural sciences with significant interest in agriculture and food applications over the past decades $[1,2]$. Since nanoscaled particles have an extremely small size, high surface to volume ratio and

c) The Author(s) 2021. This article is licensed under a Creative Commons Attribution 4.0 International License, which permits use, sharing, adaptation, distribution and reproduction in any medium or format, as long as you give appropriate credit to the original author(s) and the source, provide a link to the Creative Commons licence, and indicate if changes were made. The images or other third party material in this article are included in the article's Creative Commons licence, unless indicated otherwise in a credit line to the material. If material is not included in the article's Creative Commons licence and your intended use is not permitted by statutory regulation or exceeds the permitted use, you will need to obtain permission directly from the copyright holder. To view a copy of this licence, visit http://creativeco mmons.org/licenses/by/4.0/. The Creative Commons Public Domain Dedication waiver (http://creativecommons.org/publicdomain/ zero/1.0/) applies to the data made available in this article, unless otherwise stated in a credit line to the data. 
active surface area, their unique properties and superior functionalities greatly differ from those of micro-sized particles or fibers [3]. The advantages of the application of nanomaterials in agriculture are in particular to improve pesticides activity, enhance the yield and quality of crops, reduce agrochemicals usage and cost in plant protection, minimize nutrient losses in fertilization, and scale down the environmental pollutions $[4,5]$. Nanoformulations of pesticides have been rapidly developed to replace classic pesticides since the millennium [6]. Nanoparticles may act as plant growth promotors, and/ or enhancers for stress tolerance to harsh environment. Their functionality and efficacy not only depend on their physiochemical properties, but also application methods (foliar delivery, hydroponics, soil). Doses of application make great effects in effectiveness [7]. Liu et al.[8] proposed that nano-scaled formulation of pesticide provided a better spatial distribution of the pesticide and uniformity of coverage on leaf surfaces during enhancing the insecticidal efficiency. Similar as other nano-formulated products, excessive utilization of engineered inorganic, or manipulated nanoparticles in agriculture might also have an unknown consequences or co-contamination in soil, ground water, and food products, even potentially toxic to human and plants [2]. Therefore, alternatives of nanopesticide formulation with biomaterials have aroused great interest recently.

Chitin is a naturally polymer in the form of microfibrillar arrangements in fungal cell walls, crustacean shells, and insect exoskeletons, constituting of randomly distributed long - chain of N-acetyl-D-glucosamine (GlcNAc), $\beta$ (1-4) linked residues of $\mathrm{N}$-acetyl-2 amino-2-deoxyD-glucose, and 2-amino-2-deoxy-D-glucose residues (GlcN) [9]. Native chitin polymer occurs in three forms including $\alpha-, \beta$-, and $\gamma$-types crystallites, which depends on their biological origin [10]. Most natural chitin has $\alpha-$ type crystal structure with strong intermolecular hydrogen bonding, while $\beta$ - type chitin is presented in squid pens and tubeworms [11]. Chitin is insoluble in water and most organic solvents due to its highly hydrophobic structure. These three forms of chitin are all stable after boiling in $5 \% \mathrm{KOH}$ or $\mathrm{NaOH}, \alpha$-chitin is even more thermodynamically stable than $\beta$ - chitin [12].

Chitosan is the most important derivative of chitin but it is referred only when the degree of deacetylation reaches circa $50 \%$ or higher, depending on the origin of the polymer, and becomes soluble in aqueous acidic solution [13]. Chitin and its derivatives have been widely applied in the food science, agriculture, cosmetics, wastewater treatment, and biomedical areas [14] due to its desirable biological properties, biocompatibility, biodegradibility, and low cytotoxicity to human and other animals [15-18]. Chitin and chitosan have been recognized as plant growth regulators, growth stimulants, and elicitors for the production of secondary metabolites acting as fertilizers, soil conditioning agents, plant disease control agents, antitranspirants, ripening retardants, and seed and fruit coatings [19-23]. Early studies showed that chitosan and chitosan-metal complexes ( e.g. chitosansilver nanoparticle) had a potential to develop a new control tools against young instar populations of malaria mosquitoes [24]. But the insecticidal activity of chitosan and chitosan-metal complexes against cotton leafworm Spodoptera littoralis and oleander aphid Aphis nerii as sucking pest were related to molecular weight and degree of deacetylation of chitosan. Chitosan with molecular weights in the range of $2.27 \times 10^{5}-5.97 \times 10^{5} \mathrm{~g} / \mathrm{mol}$ showed the highest efficacy in pest control [25]. However, chitin and chitosan are mainly distinguished not only by their solubility in dilute aqueous acids, but also related to the degree of deacetylation, and the method of preparation as well [26, 27]. Water insolubility of chitin and chitosan is the key factor limiting their use in agriculture.

Nanochitin whisker (NC) has recently drawn a growing attention in agricultural and environmental application [28-33]. NC is generally synthesized chemically or enzymatically $[34,35]$. Chitin is fairly stable under mild acidic and basic conditions. However, in a concentrated hydrochloride acid solution, deprotonated and demineralized chitin can be degraded and partial deacetylated from amorphous region of chitin microfibrils and resulted in nanocrystalline fragment, i.e. nanochitin particle or nanochitin whisker [36]. In acidic solution, some unacetylated amino-groups of the NC complexed with a proton to give $\mathrm{NH}_{3}{ }^{+}$at the crystallite surfaces. The charged crystallites particles repel each other and form a stable colloidal suspension at a concentration less than 1\% [37]. In other words, the protonation of amino group brings positively charged particle and yields polyelectrolyte in solution. The acid concentration, reaction temperature, and time are main factors influencing the products' physicochemical properties including the particle size, surface charge, and its chemico-biological properties. On the other hand, ionic strength affects the stability and charge density of nanochitin in aqueous solution [38]. Generally, the particle size of chemical synthesized nanochitin varies in the range of 50 to few microns in length and 4-80 $\mathrm{nm}$ in width depending on the hydrolysis methods and different origins of chitin [12,39].

The nanochitin whisker possesses strong biological activities, low toxicity in plant protection application [32, 40-44]. It has been reported that nanochitin particle surpasses reported biobased nanoparticles such as nanocellulose, alginate, and glucan. Its interface stability at ultralow concentrations and utilization potentialities has more advantages than other biobased nanoparticles 
in future nanopesticide formulation through selfassembled networks of short and long nanoparticles for oil/water interfacial super stabilization [1,45]. Nanochitin has shown great potential in various biomedical, agriculture and food applications. A recent report demonstrated that nanochitin particles are useful for functional foods formulation as a nano-emulsifier because of their strong ability to slow down lipid digestion inside the human gastrointestinal track without toxicity to humans, animals, wildlife, or the environment [38]. Based a report of cytotoxicity assay, both nanochitin particle and fiber were non-toxic to epithelial-like and fibroblast-like cell lines [46]. Zhao et al. [47] also demonstrated that chitin whisker had good biocompatibility below the concentration of $2.5 \mathrm{mg} / \mathrm{mL}$ with low toxicity to model cells of mouse bone marrow mesenchymal stem cells (mBMSCs) and rat osteosarcoma cells (UMR106) in vitro. In our previous study, nanochitin mixed with Imidacloprid 10\% WP showed a significant control efficiency in wheat aphid [44]. We recently reported that nanochitin conjugated with abamectin, a biopesticide for insect pests control, had a great ability to control larva growth, enhancing mortality against 2 instar larvae of noctuid, and effectively reducing pesticides dosage by $50 \%$ [43]. However, the insecticidal activity and toxicity of $\mathrm{NC}$ has not been systemically explored at present. The hypothesis of this study is that NC can be absorbed and transported inside a biological system easily due to its small size, cationic nature. Water based nanochitin suspension is a goodcandidate in nanopesticide formulation to enhance insecticidal activity and safer to use in agriculture. The objectives of this study were to assess the synergistic effects of $\mathrm{NC}$ with chemical pesticides on piercing-sucking mouthparts insect control using wheat aphid as a model insect, and monitor the transportation pathway of NC inside insect bodies using fluorescent-labelled nanoparticles. To ensure a safer application, we studied the toxicity of $\mathrm{NC}$ against Sprague-Dawley (SD) rat as a model animal. The aim of this study is to provide innovative solutions in nanopesticide formulations and application in the pest control for future agriculture sustainability.

\section{Materials and methods}

\section{Materials}

Chitin (from shrimp shells practical grade, powder) was purchased from Sigma Aldrich (Sigma-Aldrich Co. LLC.), hydrochloric acid (36-38\%) was purchased from Shuangshuang Chemical Company (Yantai, Shandong, China), anhydrous ethanol was purchased from Fuyu Chemical Company (Tianjin, China), fluorescein isothiocyanate (FITC) was purchased from Sangon Biotech (Sangon Biotech Co., Ltd. Shanghai, China), standard
$\mathrm{HCl}$ solution (certified, $0.1 \mathrm{M}$ ), $\mathrm{NaOH}$ solution (certified, 0.1 and $1 \mathrm{M}$ ), acetic acid (glacial, certified plus), and $\mathrm{NaCl}$ (certified) were purchased from Thermo Fisher Scientific Co., Ltd. (Shanghai, China). Omethoate ( $40 \%$ EC) was purchased from Tianyi Agrochemical Crop (Zhejiang, China). Imidacloprid (10\% WP) was purchase from Hailir Pesticides and Chemicals Group (Shandong, China). Acetamiprid (40\%WG) was purchased from Shuang Xing Pesticide Co., LTD (Shandong, China).

Wheat plants were planted in the Insect Physiology Laboratory at Henan Agricultural University, China. The model aphids (Rhopalosiphum padi, Hemiptera: Aphididae) were bred in the Plant Growth Chamber for at least 30 generations in Insect Physiology and Biochemistry Laboratory of Henan Agricultural University. Adult male and nulliparous, non-pregnant female Sprague Dawley (SD) rats were obtained from Henan Laboratory Animal Center (Zhengzhou, China) and bred under specificpathogen-free conditions for Biological assay of toxicity.

The water used in the experiments was deionized water from a Millipore Direct-Q 5 ultrapure water system (resistivity at $25^{\circ} \mathrm{C}: 18.2 \mathrm{M} \Omega \mathrm{cm}$ ). All other chemicals were analytical grade.

\section{Preparation of nanochitin}

Nanochitin was prepared according to the method described by Xue et al. [32] with some minor modifications. In brief, shrimp chitin powder was hydrolyzed in $3 \mathrm{M}$ of $\mathrm{HCl}$ solution at a reaction ratio of chitin to $\mathrm{HCl}$ of $1 \mathrm{~g}$ : $400 \mathrm{~mL}$ for $90 \mathrm{~min}$ at $90{ }^{\circ} \mathrm{C}$ under an overhead stirring at $150 \mathrm{rpm}$ to digest the amorphous regions of chitin. The reaction was repeated three times at same condition. After each hydrolysis, the reaction was stopped by cooling the reaction flask in an ice-water bath, the treated chitin was recovered by centrifugation at $9000 \mathrm{pm}$ for $15 \mathrm{~min}$ under cooling $\left(4^{\circ} \mathrm{C}\right)$, and same amount of fresh reagent was then added to the reaction system to finish the next round reaction. Following the final step of hydrolysis, the reaction was stopped by 10 -fold dilution of the reaction medium with pre-cooled deionized water. The product was collected by centrifugation for $15 \mathrm{~min}$ at $9000 \mathrm{rpm}$ under cooling $\left(4^{\circ} \mathrm{C}\right)$ and redispersed in deionized water after discarding of the supernatant. For removal of the remaining acid, the final product was dialyzed against deionized water with regenerated cellulose dialysis tubing (Spectra/Por4, Spectrum Laboratories, MWCO 12-14 $\mathrm{kDa}$ ) until the $\mathrm{pH}$ of the dialysis water stayed constant. The obtained suspension was sonicated under ice-bath cooling for $15 \mathrm{~min}$ at 35\% output with a $500 \mathrm{~W}$ ultrasonic processor (Sonics \& Materials, model VC-505). Finally, the suspension was filtered through a $1.0 \mu \mathrm{m}$ and then $0.45 \mu \mathrm{m}$ PVDF syringe filter. The stock suspension of nanochitin was stored at $4{ }^{\circ} \mathrm{C}$ for future characterization. 


\section{Characterization of nanochitin}

The concentration of nanochitin suspension (NCs) was measured by oven-dry for $4 \mathrm{~h}$ at $80^{\circ} \mathrm{C}$. Briefly, $1.0 \mathrm{~mL}$ of NCs was deposited and weighted before and after drying for $4 \mathrm{~h}$ in an oven at $80{ }^{\circ} \mathrm{C}$. The concentration was calculated based on the weight loss of NCs, the measurement was conducted in triplicate. The concentration in this study was generally in the range of $0.3-0.6 \%(\mathrm{w} / \mathrm{v})$.

The morphology of the nanochitin particles was analyzed by field-emission scanning electron microscopy (FE-SEM) and transmission electron microscopy (TEM) respectively. For FE-SEM, a drop of $10 \mu \mathrm{L}$ of NCs $(0.015 \% \mathrm{w} / \mathrm{v})$ was deposited onto a conductive double-sided carbon adhesive tape (SPI Supplies and Structure Probe, Inc.) mounted onto a standard SEM stub and allowed to dry under ambient conditions. Prior to imaging, the SEM samples were coated with platinum. Images were recorded with a JSM-6490LV scanning electron microscope at an accelerating voltage of $10.0 \mathrm{kV}$ and a working distance of $9.5 \mathrm{~mm}$. About 10-15 particles on the image were randomly selected to measure the geometric sizes (length and width) using automated software (JEOL Scanning Electron Microscope software, 6490 SEM). For TEM, a drop of the NCs $(0.075 \% \mathrm{wt} / \mathrm{v})$ was deposited on carboncoated copper grid (200 meshes). The excess liquid was absorbed by filter paper, and 1 drop of $2 \%$ uranyl acetate negative stain was added before drying. The excess solution was blotted with a filter paper and allowed to dry naturally by evaporation. The sample grid was observed using a JEOL electron microscope (JEM 2100) with an accelerating voltage of $80 \mathrm{kV}$. The images were acquired with a $4 \mathrm{k}$ CMOS camera.

For the particle size and zeta potential measurement, a $0.1 \%(\mathrm{~W} / \mathrm{V})$ of NCs was diluted from stock solution by deionized water without adjustment of the $\mathrm{pH}$ and ionic strength. The effective particle size and zeta potential of nanochitin particles were measured based on dynamic light scattering (DLS) technique by 90 Plus Zeta (Brookhaven Inc.) at $25{ }^{\circ} \mathrm{C}$. Measurements were performed in triplicate at $25^{\circ} \mathrm{C}$.

The amino group density of the nanochitin was measured in triplicate by conductometric titration with FE30 conductivity meter with an LE703 conductivity probe. The initial $\mathrm{pH}$ of the suspension was adjusted with a standard $\mathrm{HCl}$ solution $(0.1 \mathrm{M})$, having an ionic strength of $0.1 \mathrm{M}$. A standard $\mathrm{NaOH}$ solution $(0.01 \mathrm{M})$ was added in drop-wise under stirring to $20 \mathrm{~mL}$ of a $0.27 \%(\mathrm{w} / \mathrm{v})$ of NCs, at every 10 th drop, the conductivity of the NCs was recorded. The amino group density was calculated from the titrant volume between the two equivalence points. All measurements were performed in triplicate.

\section{Preparation of fluorescent-labelled nanochitin}

Fluorescent-labelled nanochitin particles were prepared following method described by Zhao et al. [48] with some modification. In brief, about $200 \mathrm{mg}(0.33 \% \mathrm{mg} / \mathrm{ml}, 60$ $\mathrm{mL}$ ) of purified nanochitin was re-dispersed in $60 \mathrm{~mL}$ of $1 \%(\mathrm{v} / \mathrm{v})$ acetic acid solution followed by the addition of $0.1 \mathrm{M} \mathrm{NaOH}$ solution to adjust $\mathrm{pH}$ to 6.2. FITC was dissolved in methanol at $10.0 \mathrm{mg} / \mathrm{mL}$ concentration, and 3 $\mathrm{mL}$ of FITC solution was slowly added to the NCs. The labelling ratio of the amino group in total glucosamine unit was controlled with a final concentration of FITC in the reaction medium. The reaction between the isothiocyanate group of FITC and the amino group of the D-glucosamine residue was allowed to proceed for 4 hours in the dark at room temperature. FITC-labelled nanochitin particles (FNC) were centrifuged at 12,000 rpm for 15 min and washed with methanol extensively until there was complete absence of free FITC fluorescence signal in the washing medium, which was detected using UVvis spectrophotometer (UV-2000, UNICO Instrument Co., Ltd., Shanghai), and the values for peak fluorescence intensity was determined at $490 \mathrm{~nm}$. The standard absorbance of FITC was calibrated using dilutions of FITC in methanol. Fluorescent intensity of FNC was examined by fluorescent microscopy, which excitation and emission spectrum peak wavelength of FITC was at approximately $495 \mathrm{~nm}$ and $519 \mathrm{~nm}$ respectively. The labelling efficiency was approximately one FITC molecule per 70 of D-glucosamine residues of nanochitin. Typical reaction yield was $85 \%$.

\section{Insecticidal activity of nanochitin against pest insect Spray contact}

This study was carried out using wheat aphid as piercing-sucking mouthparts insect. The insecticidal activity assay followed the Guideline for Laboratory Bioassay of Pesticides (Ministry of Agriculture of the People's Republic of China, NY/T 1154.9-2008). In brief, wheat aphid $R$. padi was obtained after at least 30 generation breeding from the Insect Physiology and Biochemistry Laboratory of Henan Agricultural University, 15 of healthy and active aphids were selected for a standard screening toxicity test by spraying contact method with difference concentration of $\mathrm{NCs}$ and dilutions of three insecticides $40 \%$ Omethoate (EC), 40\% Acetamiprid (WG), and $10 \%$ Imidacloprid (WP), as well as their mixtures. The selected aphids were carefully inoculated onto the leaf of wheat plant using a soft brush. NCs with concentrations of $10 \mathrm{mg} / \mathrm{L}, 30 \mathrm{mg} / \mathrm{L}$, and $50 \mathrm{mg} / \mathrm{L}$ were diluted from a stock suspension $(0.38 \% \mathrm{w} / \mathrm{v})$ with deionized water, respectively. Recommended application concentrations of 1500 -fold solution $(1500 \times, 1$ in 1500 parts dilution) of $40 \%$ Omethoate (EC), 16,000-fold solution $(16,000 \times$, 
1 in 16,000 parts dilution) of 40\% Acetamiprid (WG), and 3000 -fold solution (3000×, 1 in 3000 parts dilution) of $10 \%$ Imidacloprid (WP) were prepared by diluting 40\% Omethoate (EC), 40\% Acetamiprid (WG), and 10\% Imidacloprid (WP) with tap water, respectively. The control efficiency was compared among the treatments of the dilutions of NCs, $1500 \times$ solution of $40 \%$ Omethoate (EC), and 16,000 $\times$ solution of $40 \%$ Acetamiprid (WP), as well as their mixtures with NCs, respectively. The $1500 \times$ solution of $40 \%$ Omethoate served as a control. Aphids were fed under the condition of $24-26{ }^{\circ} \mathrm{C}, 60 \%-80 \%$ of relative humidity, the photoperiod $\mathrm{L}: \mathrm{D}=16: 8$. The number of aphids alive was checked at interval times after treatment. To define aliveness of aphid after treatment, a soft slender brush was adopted to gently touch the body of aphid, those of irresponsive bodies were counted as dead, and corrected death rate and the mortality were then calculated. All treatments were repeated three times.

\section{Continuous immersion test}

Continuous immersion test was carried out by leafdipping method following the Guideline for Laboratory Bioassay of Pesticides-Ministry of Agriculture of the People's Republic of China NY/T 1154.4-2008. Nanochitin with concentration of $10 \mathrm{mg} / \mathrm{L}, 30 \mathrm{mg} / \mathrm{L}$, and $50 \mathrm{mg} / \mathrm{L}$ were also used to evaluate the control efficiency and synergistic effects on mortality of aphid when combined with conventional pesticides in this study. The $1500 \times$ dilution of $40 \%$ Omethoate served as a control. The control efficiency was compared with different concentrations of NCs and the mixtures with $3000 \times$ dilution of $10 \%$ Imidacloprid (WP), $1500 \times$ dilution of $40 \%$ Omethoate (EC), and 16,000 $\times$ dilution of $40 \%$ Acetamiprid (WP), respectively. For the treatment, the healthy wheat plants with roots were selected, fully expanded true leaves from wheat plants were dipped in NCs for 30 $\mathrm{s}$ and air-dried for 30-60 min. The treated leaves were then placed on filter papers in Petri dishes (three petri dishes per concentration). Once treated leaves had relatively dried, 15 of healthy adult aphids were inoculated to each treatment. The treatments were kept in a constant environment room maintained at $26{ }^{\circ} \mathrm{C} \pm 2{ }^{\circ} \mathrm{C}, 65 \pm 5 \%$ RH, with $12 \mathrm{~h}: 12 \mathrm{~h}$ (light: dark) photoperiods. Mortality was recorded at $24,48,72$, and $96 \mathrm{~h}$ after treatment under a microscope. Aphids unable to move and showing symptoms of poisoning were counted as death. Experiments were carried out in triplicate.

The model used for calculating the mortality was based on the Guideline for Laboratory Bioassay of Pesticides Ministry of Agriculture of the People's Republic of China NY/T 1154.4-2008, corrected mortality were calculated according to following equation:
Corrected mortality $(\%)=\left(P-P_{0}\right) /\left(1-P_{0}\right) \times 100$

where: $\mathrm{P}$ is the percentage of mortality of treated insects, $\mathrm{P}_{0}$ is the percentage of mortality of insects in the untreated control.

\section{Biological assay of toxicity}

The biological assay was conducted by School of Public Health of Zhengzhou University (Zhengzhou, China) following the Toxicological Test Methods of Pesticides for Registration-State Standard of the People's Republic of China-GB15670-1995.

\section{Acute oral toxicity}

Acute oral toxicity of nanochitin was evaluated using Sprague Dawley (SD) rats at School of Public Health of Zhengzhou University (Zhengzhou, China), based on Good Laboratory Practice (GLP). This experiment was conducted in accordance with the authorized guideline for care and use of the laboratory animals. Five male and five female SD rats in specific pathogen-free (SPF) grade were selected and kept on an ordinary diet and were breeding at ambient conditions $\left(21-25{ }^{\circ} \mathrm{C}\right.$, relative humidity $50-70 \%$ ). The rats were divided into two groups, 5 rats each group with an average body weight of 189-201 g. Permit limited tests method was used, $5000 \mathrm{mg} / \mathrm{kg}$ body weight (BW) of the test animal was administered orally by gavage to 5 rats that have been overnight fasted, oral administration of NCs (1.0 $\mathrm{mL} / 100 \mathrm{~g} \mathrm{BW}$ ) in one oral gavage dose for 2 weeks. After 2 weeks of observation, animal weight, symptoms of poisoning, and death were recorded. The death of the animal for gross pathological examination was carried out at the end of the test. The value of $\mathrm{LD}_{50}$ was the average of each treatment.

\section{Acute dermal toxicity}

The tested SD rats and the method were same as described above. For dermal toxicity test, permit limited tests of $2000 \mathrm{mg} / \mathrm{kg} \bullet \mathrm{BW}$ of the test animals was used. Before test, the hair on the animal back was shaved and the damage of the skin was observed for $1 \mathrm{~d}$. The test was carried out by placing NCs on an area of $4.5 \mathrm{~cm}^{2}$ where the animal's skin has been shaved. The applied area was then covered with sterilized gauze. After $4 \mathrm{~h}$ adsorption, the treated area was washed with warm water and then observed the changes for 14 days, and all gross pathological changes were recorded. Necropsy of all animals 
was carried out and all gross pathological changes were recorded.

\section{Statistical analysis}

The data represents the means for each treatment and compared statistically with a one-way analysis of variance LSD (ANOVA, $\alpha=0.05$ ). All measurements were carried out in triplicate. Standard deviation was used to specify variability among triplicates. Differences at $\mathrm{p}<0.05$ or $\mathrm{p}<0.01$ were considered to be statistically significant. Data was analyzed using SPSS 22.0 software for Windows (IBM, New York, NY, USA).

\section{Results and discussion}

\section{Characterization of synthesized nanoparticles}

The morphology of nanochitin particle was studied by TEM and FE-SEM respectively. Similar morphology of the particles was observed on both SEM image and TEM image (Fig. 1). The length of the particles was in the range of $50-150 \mathrm{~nm}$, the width was $15-50 \mathrm{~nm}$, which makes a great agreement with previous reports [32].

DLS measurements are commonly technique used to determine the true state of particles in media [32]. The determination of size, zeta potential, and polydispersity (PDI) parameters are defined in the ISO standard documents 13321:1996 E and ISO 22412:2008 [49]. PDI is an indication of their quality with respect to the size distribution. Values of PDI greater than 0.7 indicate that the sample has a very broad size distribution and is probably not suitable for the DLS technique [50]. Based on DLS analysis, 90\% of the nanoparticles in this study were in the range of 37.3 to $140.0 \mathrm{~nm}$ (Fig. 2, left) with a PDI of 0.247 , showing that the nanochitin whiskers have a high dispersibility in aqueous solution. The zeta potential of $0.1 \%(\mathrm{w} / \mathrm{v})$ nanochitin suspension was $26.67 \mathrm{mV}$ with a data retention of $100 \%$, showing effective enrichment amino groups in nanochitin (Fig. 2, right).

The amino group density of nanochitin was determined by conductometric titration. Figure 3 shows typical conductometric titration curves which had three sections. The initial linear decrease in conductivity was due to the neutralization of $\mathrm{HCl}$ and the lower mobility and molar conductivity of $\mathrm{Na}^{+}$with respect to $\mathrm{H}^{+}$. After the first equivalence point, the decrease in conductivity slowed down. The middle section of the conductivity curve corresponded to the titration of the amino groups of nanochitin. At the second equivalence point, the conductivity started to increase upon additional $\mathrm{NaOH}$ because of excess of sodium and hydroxyl ions during the titration. Based on the calculation, the amino group density of nanochitin was $6.224 \mathrm{~mol} / \mathrm{kg}$.

\section{Promotive effect of nanochitin whisker to chemical aphicides on mortality of wheat aphid}

Aphids are soft-bodied insects with piercing sucking mouthparts and feed on plant sap. R. padi is one of the major cereal pests of winter wheat and threatened wheat production in China. Control of R. padi has relied heavily on chemical insecticides [51, 52]. However, massive application of insecticides have resulted in insect resistance and raised serious human health and environmental concerns $[53,54]$.

Omethoate, imidacloprid and acetamiprid had significant toxic effects on wheat aphid, but they are not suitable to be used when wheat aphids outbreaks because of its short persistent period. For example, dilution of $40 \%$ Omethoate EC has displayed poor field control efficacy suggesting that wheat aphids had produced resistance to this insecticide [55]. Imidacloprid is a neonicotinoid insecticides as a new bionic pesticides. The insecticidal activity of imidacloprid is mainly acting on the acetylcholine receptor $(\mathrm{AChR})$ in the nervous system of insects [54]. For future sustainable agricultural production, incorporation of nanotechnology within pesticides formulation will be a new tool to lower the indiscriminate use of conventional pesticides and for safe environmental applications [56].

Chitin and its derivatives have been proved lack of toxicity and not expected to harm people, pets, and wildlife, generally recognized as safe (GRAS) status as a food additive by the U.S. Food and Drug Administration [57-59]. Nanochitin material has been widely used in biomedical development with good biocompatibility, biodegradability, and non-cytotoxicity [60]. Zhao et al. [47] reported that nanochitin whiskers exhibited low toxicity at concentration lower than $50 \mu \mathrm{g} / \mathrm{mL}$ and had better cytocompatibility at $200 \mu \mathrm{g} / \mathrm{mL}$ concentration. Therefore, nanochitin would not cause damages to non-target populations.

To investigate the insecticidal activities and enhancement of nanochitin to chemical insecticides against wheat aphid, different concentration of NCs and its mixtures with dilutions of chemical pesticides, i.e. $1500 \times$ solution of $40 \%$ Omethoate (EC), $16,000 \times$ solution of $40 \%$ Acetamiprid (WG), and $3000 \times$ of $10 \%$ of Imidacloprid (WP), were used for the treatments. $R$. padi was used as a model insect and tested by sprayingcontact and continuous immersion methods respectively. We first tested the effectiveness of different concentrations of NCs and its mixtures with $1500 \times$ solution of $40 \%$ Omethoate (EC) at 1:1 by volume to obtain an optimal concentration of nanochitin in the mixture. The effects of nanochitin and its mixture with omethoate on aphid control were showed in Fig. 4 for spraying-contact and continuous immersion methods, respectively. Figure $4 \mathrm{a}$ showed that, at early stage, nanochitin alone by spraying contact method was unable 


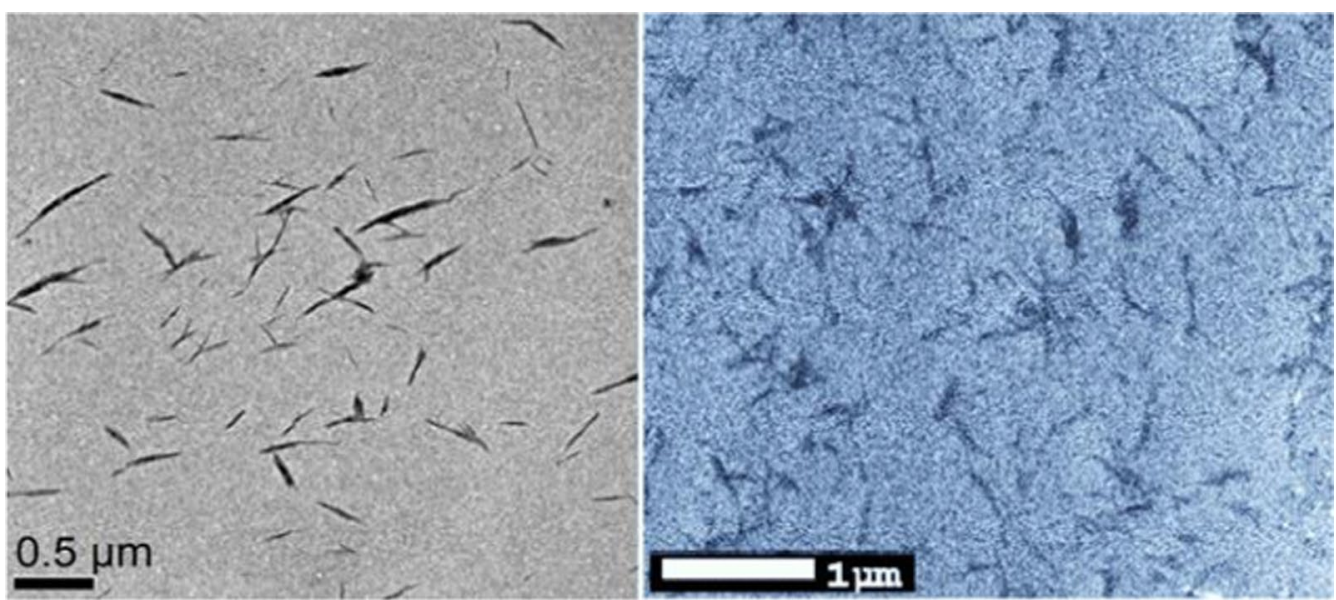

Fig. 1 Electron microscopy images of chemically hydrolyzed nanochitin particles. Left-TEM image (sale bar, $0.5 \mu$ m), right-FE-SEM image (sale bar, $1.0 \mu \mathrm{m})$
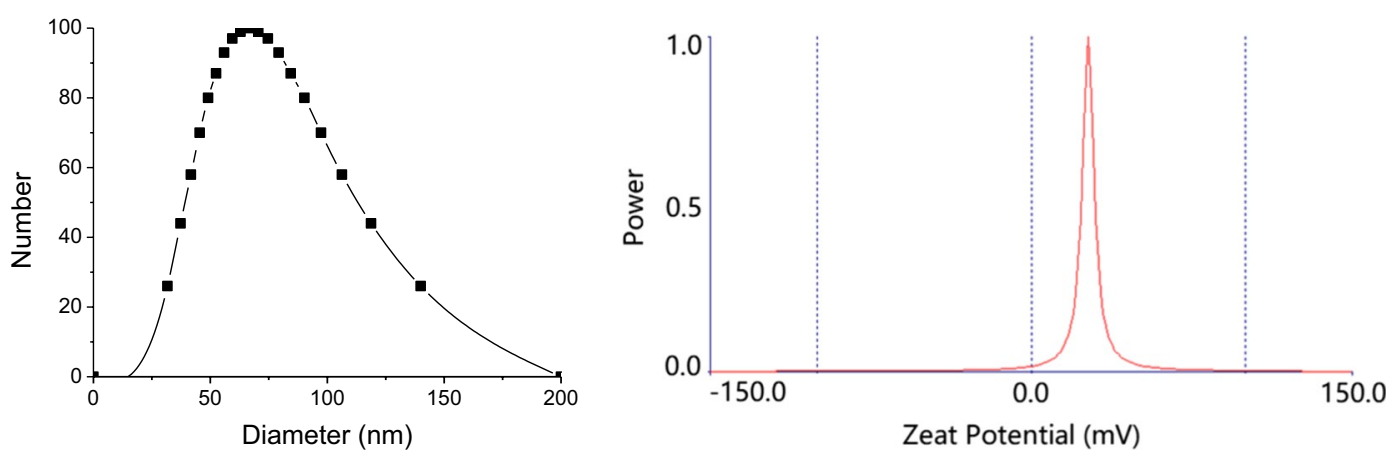

Fig. 2 The size (left) and zeta potential (right) distributions of nanochitin particles examined by dynamic light scattering

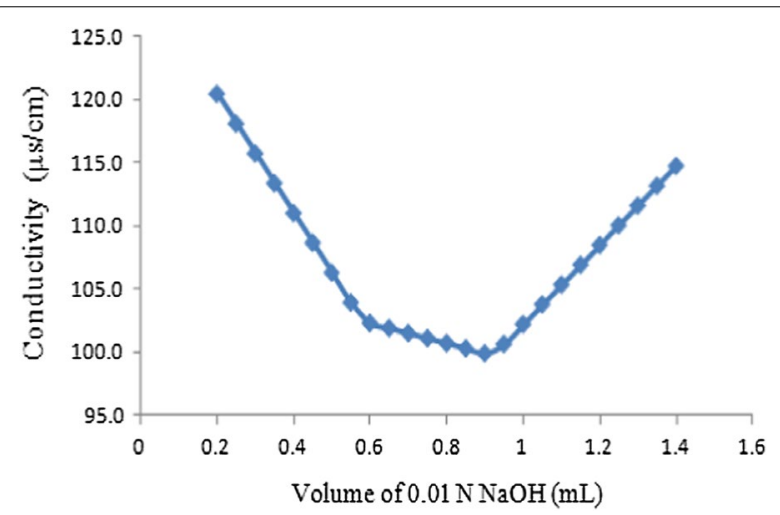

Fig. 3 Conductometric titration curves for the determination of the amino group density of nanochitin

to effectively control aphids, the corrected mortalities of aphids treated with nanochitin alone were much lower than $1500 \times 40 \%$ Omethoate (EC). However, when mixed with $1500 \times 40 \%$ Omethoate (EC), the corrected mortalities of aphids were all significantly enhanced after $4 \mathrm{~h}$ treatment and there was no significant difference among the treatments of the mixtures with nanochitin at concentration of $30 \mathrm{mg} / \mathrm{L}(\mathrm{A}+\mathrm{C})$, $50 \mathrm{mg} / \mathrm{L}(\mathrm{A}+\mathrm{D})$, and $1500 \times 40 \%$ Omethoate $(\mathrm{EC})$. After $8 \mathrm{~h}$ treatment, there is no significant difference in corrected mortality of aphids treated with all mixtures and $1500 \times 40 \%$ Omethoate (EC). After $12 \mathrm{~h}$ treatment, the corrected mortalities of aphid treated with $50 \mathrm{mg} / \mathrm{L}$ of nanochitin alone reached $75.0 \%$ with a significant increase compared to the treatments with $10 \mathrm{mg} / \mathrm{L}$ and $30 \mathrm{mg} / \mathrm{L}$. After $12 \mathrm{~h}$ treatment by the mixtures of nanochitin with $30 \mathrm{mg} / \mathrm{L}(\mathrm{A}+\mathrm{C})$ and $50 \mathrm{mg} / \mathrm{L}(\mathrm{A}+\mathrm{D})$, the corrected mortalities of aphids reached $81.4 \%$ and $97.7 \%$. The control efficiency was dramatically improved by the mixture of $50 \mathrm{mg} / \mathrm{L}$ with $1500 \times 40 \%$ Omethoate $(E C)$, and there was a significant enhancement compared to other treatments, indicating that $50 \mathrm{mg} / \mathrm{L}$ was 
an optimal concentration to make an effective mixture with chemical pesticides. In application practice, the dosage of the chemical pesticide and nanochitin in the mixtures were all reduced to half due to half-by-half in volume mixing. Similarly, when continuous immersion method was employed (Fig. 4b), the corrected mortalities of the aphid, treatments with nanochitin alone at all three concentrations were significant lower than that of $1500 \times 40 \%$ Omethoate (EC) dilution after 1 day treatment. But the corrected mortalities of the aphids treated with the mixtures were $56.8 \%, 59.1 \%$, and $68.2 \%$ for the treatments of mixtures with $10 \mathrm{mg} / \mathrm{L}, 30 \mathrm{mg} / \mathrm{L}$, $50 \mathrm{mg} / \mathrm{L}$ of nanochitin, respectively. There was a significant improvement in the mortality of aphid treated with the mixture of $50 \mathrm{mg} / \mathrm{L}$ nanochitin comparing with those of $1500 \times 40 \%$ Omethoate (EC) and mixtures with $10 \mathrm{mg} / \mathrm{L}$ and $30 \mathrm{mg} / \mathrm{L}$. After 2 days treatment, the corrected mortalities of aphids were $79.6 \%, 86.4 \%, 81.8 \%$, and $95.5 \%$ for the treatments of $1500 \times 40 \%$ Omethoate (EC), mixture with $10 \mathrm{mg} / \mathrm{L}, 30 \mathrm{mg} / \mathrm{L}$, and $50 \mathrm{mg} / \mathrm{L}$ of nanochitin, respectively. There was no significant difference among these treatments other than those of treatments with nanochitin alone. We also found that a concentration of $50 \mathrm{mg} / \mathrm{L}$ of NCs had the highest effects on aphid's control compared with $10 \mathrm{mg} / \mathrm{L}$ and $30 \mathrm{mg} / \mathrm{L}$ of NCs either applied alone or in the mixtures with $1500 \times 40 \%$ Omethoate (EC). This result approved that nanochitin has a strong capability to increase the effectiveness of commonly used chemical pesticide, where as a mixture of chemical insecticide with nanochitin significantly decreases the usage of both components by half. It also offers a great potential to reduce the residue and pollution of agrichemicals in agriculture applications.

More synergistic effects of nanochitin on commonly used pesticide on insecticidal efficacy were investigated in a separate experiment. Three commonly used pesticides including $3000 \times$ dilution of $10 \%$ Imidacloprid (WP), $16,000 \times$ dilution of $40 \%$ Acetamiprid (WG), and $1500 \times$ dilution of $40 \%$ Omethoate (EC, $1500 \times$ ), as well as their mixtures with $50 \mathrm{mg} / \mathrm{L}$ of NCs (1:1 by volume) were used to evaluate the improvement of insecticidal efficacy in aphid control either by spraying-contact (Fig. 5a) or continuous immersion method (Fig. 5b). Figure 5a showed that at first $4 \mathrm{~h}$ treatment by spraying contact method, $50 \mathrm{mg} / \mathrm{L}$ of NCs has a low efficiency in aphid control comparing with three chemical insecticides. However, when treated with the mixtures of nanochitin with dilutions of Omethoate and Acetamiprid, the mortality of aphid significantly increased compared to the treatment of nanochitin alone. After $8 \mathrm{~h}$ treatment, the corrected mortalities of aphids in treatments with the mixtures were all significantly enhanced. After $12 \mathrm{~h}$ treatment, the corrected mortalities reached $80 \%$ or above in all treatments. The aphids treated with continuous immersion method (Fig. 5b), the control efficacy of nanochitin was almost the same as other treatments after 1 days. After 2 days treatment, the corrected mortalities of aphids were all great than $80 \%$ and there was no significantly differences among the treatments of nanochitin and its mixtures with the chemical pesticide dilutions. The usages of pesticides in the mixtures with $50 \mathrm{mg} / \mathrm{L}$ of nanochitin were all reduced by $50 \%$, demonstrating a great significance in aphids control and benefit to environmental sustainability as well.
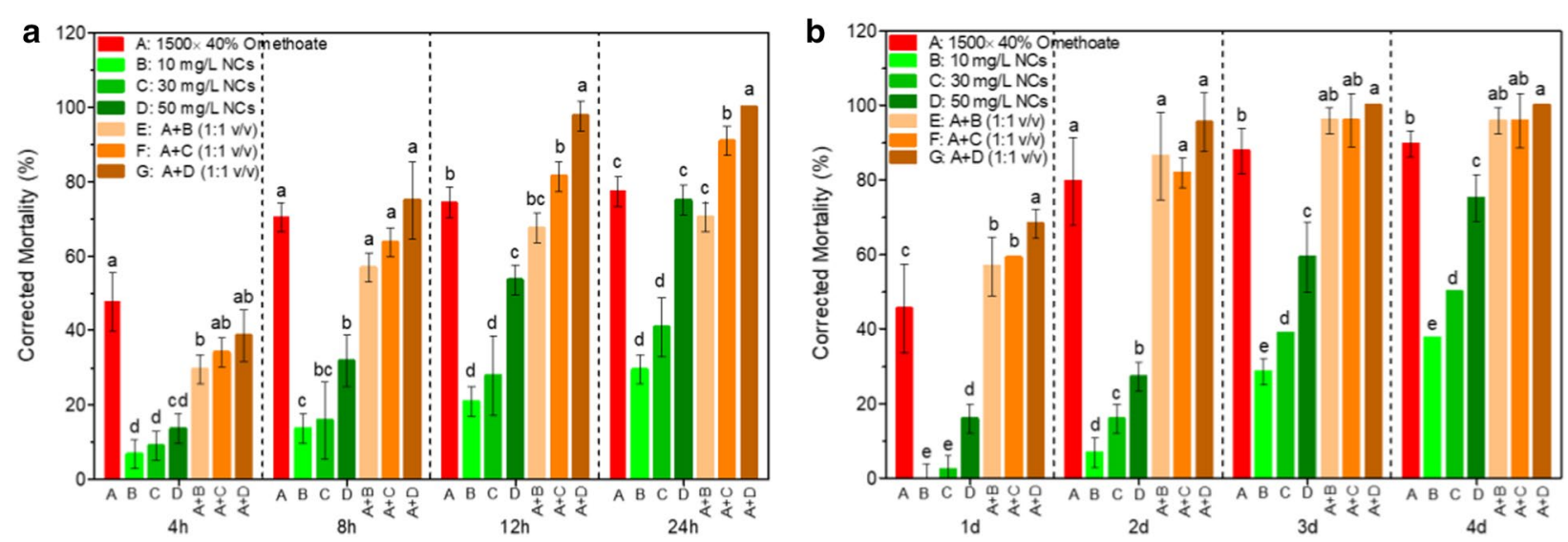

Fig. 4 Corrected mortality of $R$. padi treated with different concentration nanochitin and the mixtures with Omethoate. Experiments were carried out by a spraying contact, b continuous immersion. A-1500x dilution of 40\% Omethoate (EC), B-10 mg/L NCs, C- 30 mg/L NCs, D-50 mg/L NCs. The mixtures of $\times 1500$ dilution of $40 \%$ Omethoate $(E C)$ with NCs were made by 1:1 in volume. Data are the means of three measurements. Error bars represent one standard deviation. Different letters above the bars represent significance at $p<0.05$ 
To compare the corrected mortality for $R$. padi between different treatment methods, the data of treatments of $1500 \times$ dilution of $40 \%$ Omethoate (EC) and $50 \mathrm{mg} / \mathrm{L}$ of nanochitin in different treatment methods were selected and analyzed statistically. The results showed that spray contact method was more effective treatment method (Fig. 6). There was a significant difference between spray contact and continuous immerse methodsafter $12 \mathrm{~h}$ treatment. For the treatment of $1500 \times$ dilution of $40 \%$ Omethoate (EC), the significant difference between two methods was at significance level of $p<0.05$, however, the significant difference for the treatments of $50 \mathrm{mg} / \mathrm{L}$ alone and its mixture with $1500 \times$ dilution of $40 \%$ Omethoate (EC) was at the significance level of $\mathrm{p}<0.01$. After $24 \mathrm{~h}$ treatment, no significant difference for $1500 \times$ dilution of $40 \%$ Omethoate (EC) and its mixture with $50 \mathrm{mg} / \mathrm{L} \mathrm{f}$ nanochitin between these two treatment methods. But spray contact for $50 \mathrm{mg} / \mathrm{L}$ of nanochitin alone was more effective in aphid control, the mortality of aphid between these two methods has a significant difference at significance level of $\mathrm{p}<0.01$.

Overall, nanochitin alone in a range of $10-50 \mathrm{mg} / \mathrm{L}$ has a limited control efficiency in aphid control. When associated with chemical insecticides nanochitin significantly improved the insecticidal activity and greatly reduced chemical pesticide use. The synergistic effects of nanochitin whisker to chemical pesticides on the aphids control might be attributed to its small size and high surface area. It has been reported that $\alpha$-chitin nanocrystals from shrimp shells exhibited exceptionally high surface area near $350 \mathrm{~m}^{2} / \mathrm{g}$ [35], giving a great opportunity to associate with chemical pesticide. The results in this study also make a great agreement with previous reports $[2,43,44]$.
Moreover, an interesting phenomenon was observed during feeding with NCs (Additional file 1: Fig S1). Aphids stopped suckling after inoculated on the treated leaves (Additional file 1: Fig S1a). Some aphids moved away from the leaves (Additional file 1: Fig S1b) and some died (Additional file 1: Fig S1c) after $4 \mathrm{~h}$ treatment. It might indicate that nanochitin may have another effect on aphid behavior as an antifeedant. More study will be conducted in near future.

\section{Uptake and translocation of nanochitin whisker inside aphids}

The toxicological mechanism of nanochitin whisker in aphid control and promotable activity to chemical insecticides is still unknown. Nonetheless, labelling of biomolecules by fluorescent probe has become an important tool to detect target analytes in the fields of biology and medicine. FITC is an organic dye with excitation and emission spectrum peak wavelength at approximately $495 \mathrm{~nm}$ and $519 \mathrm{~nm}$ respectively, giving it a green color examined by a fluorescent microscope. FITC and its derivatives are widely applied fluorescence reagents with high absorptivity, excellent fluorescence quantum yield and good water solubility [61]. Hassan et al.[62] demonstrated that primary amine group of D-glucosamine residue can be labelled by isothiocyanate group of FITC and used to monitor cellular localization of biomaterials in a biological system. Nanochitin particles, on the other hand, carry certain amount of free amino group on surface of the particle after acidic hydrolysis. Therefore, nanochitin could be labelled with FITC by conveniently reacting its amino group with isothiocyanate group of FITC. FNC emits intense fluorescence in the non-polar
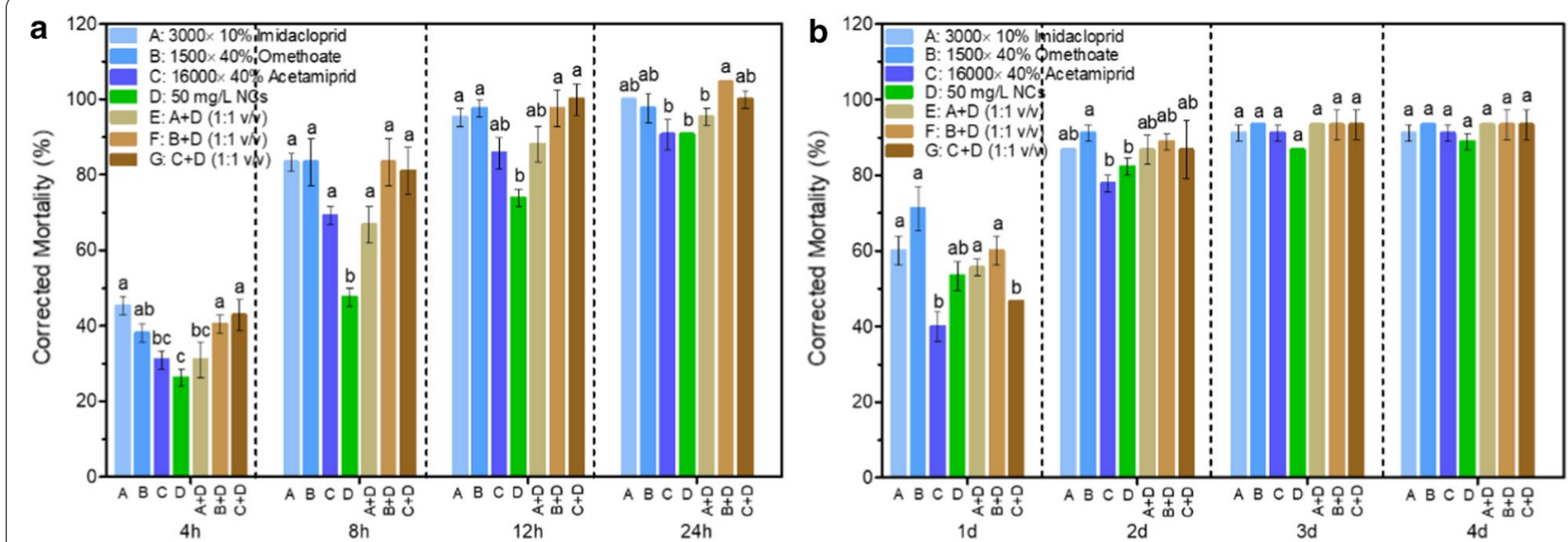

Fig. 5 Comparison of mortality of $R$. padi treated with nanochitin and combinations with commonly used insecticides. Experiments were carried out by a spraying contact, $\mathbf{b}$ continuous immersion method. A: $\times 3000$ dilution of $10 \%$ Imidacloprid (WP), $\mathbf{b} \times 1500$ dilution of $40 \%$ Omethoate (EC), C: $\times 16,000$ dilution of $40 \%$ Acetamiprid (WP), D: $50 \mathrm{mg} / \mathrm{L} \mathrm{NCs}$. The mixtures were made by volume of two components at ratio of 1:1. Data are the means of three measurements. Error bars represent one standard deviation. Different letters above the bars represent significance at $\mathrm{p}<0.05$ 


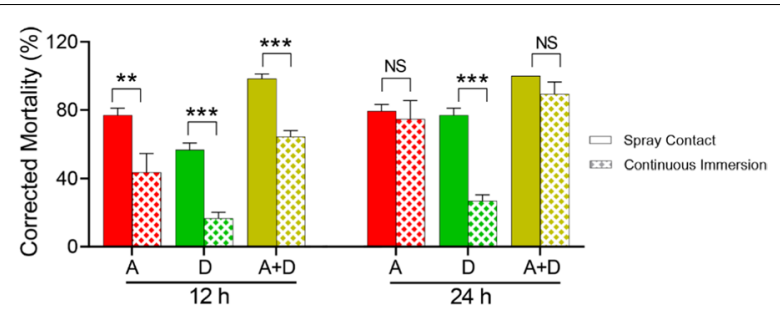

Fig. 6 Comparison of corrected mortality for R. padi treated by different treatment method. A-1500x dilution of $40 \%$ Omethoate (EC), D- $50 \mathrm{mg} / \mathrm{L}$ of nanochitin suspension, A + D: the mixture of $A$ and $D$ by $1: 1$ in volume. NS: no significant difference at level $p<0.05$, **: $p<0.05 ; * *: p<0.01$, one-way ANOVA

solvent and can be used to track the transportation pathway and acting location of nanochitin inside aphid.

To illustrate the transportation pathway of nanochitin in aphid, FNC was applied to wheat seedling, then aphids were inoculated on the leaves of treated plants. DI water served as a control for this test. The experiment was carried out by continuous immersion method. The transportation pathway and acting location of FNC particles inside aphid was examined by laser confocal scanning microscope (ZEISS LSM 700, Carl Zeiss Co., Germany) or fluorescent microscopy using Leica DM ILLED microscope (Leica DM IL-LED, Inverted Laboratory Microscopy with LED Illumination, Germany).

Figure 7 simply demonstrated the absorption and distribution of fluorescence-labelled nanochitin in aphids. The path of the absorption and translocation of the FNC over time was showed in Additional file 2: Fig S2. Theoretically, at an early stage of feeding, FNC was absorbed along with plant fluid from mouth and digestive system and distributed to the back of the body. From Additional file 2: Fig. S2 we can see that, the FNC was distributed to all parts of the body after $24 \mathrm{~h}$ (Additional file 2: Fig. S2-A). Over the time of absorption and distribution, FNC was translocated and accumulated in certain parts of the body (Additional file 2: Fig. S2-B). After $96 \mathrm{~h}$ treatment, the FNC was mostly accumulated at the cornicles area and might be emitted to outside of the body with decay of the fluorescent (Additional file 2: Fig. S2-C).

The phenomena observed in this study indicated that nanochitin can be distributed from its digestive system and relocated to other tissues. Nanochitin might continue to accumulate and remain in certain parts of the body over the time and caused significant death of aphids. It closely corresponded to the results showed in Fig. 4 that, after $12 \mathrm{~h}$ treatment, the corrected mortality of aphids treated with $50 \mathrm{mg} / \mathrm{L}$ of nanochitin alone and its mixtures with dilutions of chemical pesticides reached $80 \%$ or above, meaning that most of treated aphids dead. In our previous study, we found that NCs significantly promoted abamectin (Am) water dispersity, thermal stability, and photostability, effectively reduced Am dosage in insect pest control [43]. Am is a biogenic pesticide derived from the bacterium Streptomyces avermitilis. Its water insolubility and light-degradability greatly influence its applications in plant protection practice. Nanochitin could not only protect Am from hush environmental stability but also improve its insecticidal activity significantly when two compounds associated each other. The hydrophilic property of nanochitin and the lipophilic property of Am drove a conjugation formation but disassociated from two components at different $\mathrm{pH}$ [63]. The results in this study also showed a strong evidence that nanochitin synergistically enhanced insecticidal activity of systemic organophosphorus and neonicotinoid insecticides. When mixed with these chemicals, the use of the chemical pesticides could be significantly reduced. Moreover, foliar application of nanochitin and its combination with chemical pesticides was most effective application method to control the damage of aphids in a short period of time.

\section{Acute oral and dermal toxicity in mice}

Toxic potential of materials at nano level have drawn a lot of attention recently. Despite its potential in generating toxicity tobiological systems and the environment, materials in nanosize mayperform exceptional feats of conductivity and optical sensitivity. To evaluate the toxicity of nanochitin, standard biological assay was conducted using SD rat for acute oral and dermal toxicity determination.

The toxicity results of nanochitin to SD rat showed in Tables 1 and 2. The original NCs (stock suspension, 0.3\% $(\mathrm{w} / \mathrm{v}))$ was used as biological material. The acute oral toxicity LD50 is great than $5000 \mathrm{mg} / \mathrm{kg} \mathrm{BW}$ in male and female (Table 1), acute dermal toxicity LD50 is great than $2000 \mathrm{mg} / \mathrm{kg}$ BW (Table 2)

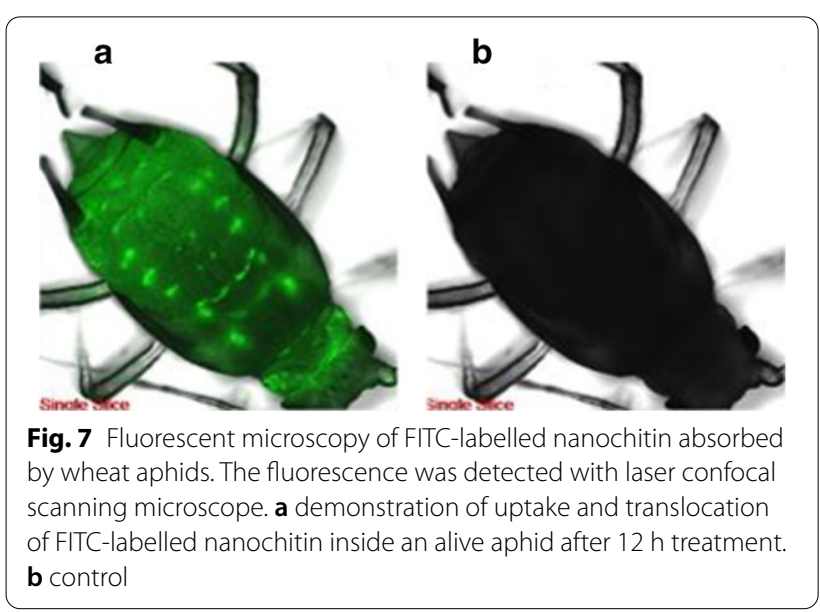


Table 1 Acute oral toxicity of NCs to mice

\begin{tabular}{|c|c|c|c|c|c|c|c|c|}
\hline \multirow[t]{2}{*}{ Gender } & \multirow[t]{2}{*}{ Dose $(\mathrm{mg} / \mathrm{kg})$} & \multirow{2}{*}{$\begin{array}{l}\text { Number } \\
\text { of Mice }\end{array}$} & \multicolumn{3}{|c|}{ Body Weight ( $x \pm$ SD) (g) } & \multirow{2}{*}{$\begin{array}{l}\text { Number of } \\
\text { Death }\end{array}$} & \multirow{2}{*}{$\begin{array}{l}\text { Death Rate } \\
\text { (\%) }\end{array}$} & \multirow{2}{*}{$\begin{array}{l}\mathrm{LD}_{50} \text { at } \mathrm{P}<0.05 \\
(\mathrm{mg} / \mathrm{kg})\end{array}$} \\
\hline & & & od & $7 d$ & $14 d$ & & & \\
\hline Male & 5000 & 5 & $195.8 \pm 4.7$ & $212.8 \pm 4.8$ & $233.6 \pm 4.8$ & 0 & 0 & $>5000$ \\
\hline Female & 5000 & 5 & $193.6 \pm 5.1$ & $207.2 \pm 5.1$ & $224.8 \pm 5.3$ & 0 & 0 & $>5000$ \\
\hline
\end{tabular}

Table 2 Acute dermal toxicity of NCs to mice

\begin{tabular}{|c|c|c|c|c|c|c|c|c|}
\hline \multirow[t]{2}{*}{ Gender } & \multirow[t]{2}{*}{ Dose $(\mathrm{mg} / \mathrm{kg})$} & \multirow{2}{*}{$\begin{array}{l}\text { Number } \\
\text { of Mice }\end{array}$} & \multicolumn{3}{|c|}{ Body Weight ( $x \pm$ SD) (g) } & \multirow{2}{*}{$\begin{array}{l}\text { Number of } \\
\text { Death }\end{array}$} & \multirow{2}{*}{$\begin{array}{l}\text { Death Rate } \\
\text { (\%) }\end{array}$} & \multirow{2}{*}{$\begin{array}{l}\mathrm{LD}_{50} \text { at } \mathrm{P}<0.05 \\
(\mathrm{mg} / \mathrm{kg})\end{array}$} \\
\hline & & & od & $7 d$ & $14 d$ & & & \\
\hline Male & 2000 & 5 & $223.0 \pm 2.7$ & $214.4 \pm 3.3$ & $263.8 \pm 3.3$ & 0 & 0 & $>2000$ \\
\hline Female & 2000 & 5 & $220.6 \pm 3.6$ & $235.0 \pm 4.0$ & $254.0 \pm 3.8$ & 0 & 0 & $>2000$ \\
\hline
\end{tabular}

Many studies have demonstrated that chitin and chitosan nanoparticles were suitable materials for biomedical applications due to its high biocompatibility, non-toxicity [47, 64]. Azuma et al. [64] reported that nanochitin whisker had a low toxicity to non-cancer cells but had obvious cytotoxicity to many kinds of cancer cells. According to Zhao et al.[47], chitin nanowhisker had good biocompatibility below the concentration of $2.5 \mathrm{mg} / \mathrm{mL}$. They also found cell viabilities of mouse bone marrow mesenchymal stem cells (mBMSCs) and rat osteosarcoma cells (UMR-106) treated with nanochitin at a concentration of $200 \mu \mathrm{g} / \mathrm{mL}$ reached $96.2 \%$ and $99.8 \%$ respectively. Solairaj et al. [65] reported that metal composited with chitin nanoparticles had stronger cytotoxicity to human breast cancer cells (MCF-7) but non-toxic to healthy cells. Our results showed that the acute oral and dermal toxicity LD50 were nontoxic to the tested mice at a concentration of $0.3 \%(\mathrm{w} / \mathrm{v}, 3,000 \mu \mathrm{g} / \mathrm{mL})$, which makes a good agreement with previous study done by Zhao et al. [47]. However, the synergistic effects of nanochitin composited with chemical pesticides on oral and dermal toxicity in mice need to be further investigated

\section{Conclusions}

Cationic chitin nanoparticles synthesized by acidic hydrolysis were rod-like whiskers. The size of the whisker was in a range of $50-150 \mathrm{~nm}$ in length and $15-50 \mathrm{~nm}$ in width examined by TEM and FE-SEM. The amino group density of nanochitin whisker in aqueous solution was $6.224 \mathrm{~mol} / \mathrm{kg}$. Nanochitin whiskers can be easily absorbed and transported in digestive system of insects through sucking by piercing-sucking mouthparts and showed insecticidal activity against piercing-sucking mouthparts insects. By treated with $30-50 \mathrm{mg} / \mathrm{L}$ of NCs, the corrected mortality of wheat aphids reached $80 \%$ or above after $12 \mathrm{~h}$ treatment. When mixed with dilution of conventional pesticides, the corrected mortality of aphid significantly enhanced up to $95 \%$ or above. Acute oral and dermal toxicity assays (for $\mathrm{LD}_{50}$ ) were performed using doses of $5000 \mathrm{mg} / \mathrm{kg} \mathrm{BW}$ and $2000 \mathrm{mg} / \mathrm{kg} \mathrm{BW}$, the results showed that nanochitin was non-toxic to the model animal SD rat. As a biocompatible and biodegradable natural polymer, nanochitin formulated pesticide system will have a great potential for agricultural applications aiming at enhancement of insecticidal activity, significant reduction of pesticides use in pests control. However, the dermal and oral toxicity for mice at higher dosages, environmental risk assessment, and toxicological mechanism of nanochitin whiskers from molecular level will be furtherinvestigated.

\section{Supplementary Information}

The online version contains supplementary material available at https://doi. org/10.1186/s12951-021-00792-W.

Additional file 1. Effect of nanochitin on aphid behavior and activity after $4 \mathrm{~h}$ treatment.

Additional file 2. Fluorescent microscopy of FITC-labelled nanochitin absorbed by wheat aphids.

\section{Acknowledgements}

Thanks to Henan Laboratory Animal Center, School of Public Health of Zhengzhou University (Zhengzhou, China) for the biological assay of toxicity. The authors also thank Prof. Amit Levy at University of Florida for editing and critiquing the manuscript.

Authors' contributions

$H W$ and $X Y$ conceived and designed the experiments. ZL performed the experiments. ZL, HW analyzed the data and wrote the manuscript. XY and SA provided technical support for the insecticidal activity, HW provided technical 
support for the preparation and characterization of nanochitin, and edited the manuscript. All authors read and approved the final manuscript.

\section{Funding}

This research was supported by grants from the Earmarked Fund for China Agriculture Research System (No. CARS-27).

\section{Ethics approval and consent to participate}

Not applicable.

\section{Consent for publication}

Not applicable.

\section{Competing interests}

The authors declare that they have no competing interests.

\section{Author details}

${ }^{1}$ Department of Entomology, College of Plant Protection, Henan Agricultural University, 450002 Zhengzhou, China. ${ }^{2}$ Department of Pesticide Science, College of Plant Protection, Henan Agricultural University, 450002 Zhengzhou, China. ${ }^{3}$ Department of Pesticide Science/Nano Agro Center, College of Plant Protection, Henan Agricultural University, 450002 Zhengzhou, China.

Received: 26 October 2020 Accepted: 3 February 2021

Published online: 16 February 2021

\section{References}

1. Sathiyabama M. Biopolymeric nanoparticles as a nanocide for crop protection. In: Pudake RN, Chauhan N, Kole C, editors. Nanoscience for Sustainable Agriculture. Cham: Springer International Publishing; 2019. p. 139-52.

2. Scott NR, Chen H, Cui H. Nanotechnology applications and implications of agrochemicals toward sustainable agriculture and food systems. J Agric Food Chem. 2018;66:6451-6.

3. Lu H, Wang J, Stoller M, Wang T, Bao Y, Hao H. An overview of nanomaterials for water and wastewater treatment. Adv Mater Sci Eng. 2016;2016:4964828.

4. Sweta B, Lalit M, Srivastava CN. Nanopesticides: a recent novel ecofriendly approach in insect pest management. J Entomol Res. 2018;42:263-70.

5. Chhipa H. Nanofertilizers and nanopesticides for agriculture. Environ Chem Lett. 2017;15:15-22.

6. Agathokleous E, Feng Z, lavicoli I, Calabrese EJ. Nano-pesticides: a great challenge for biodiversity? The need for a broader perspective. Nano Today. 2020;30:100808.

7. Zhao L, Lu L, Wang A, Zhang H, Huang M, Wu H, Xing B, Wang Z, Ji R. Nano-biotechnology in agriculture: Use of nanomaterials to promote plant growth and stress tolerance. J Agric Food Chem. 2020;68:1935-47.

8. Liu Y, Tong Z, Prud'homme RK. Stabilized polymeric nanoparticles for controlled and efficient release of bifenthrin. Pest Manag Sci. 2008;64:808-12.

9. Kaczmarek MB, Struszczyk-Swita K, Li X, Szczęsna-Antczak M, Daroch M. Enzymatic modifications of chitin, chitosan, and chitooligosaccharides. Front Bioeng Biotechnol. 2019;7:243-3.

10. Moussian B. Chitin: structure, chemistry and biology. In: Yang Q, Fukamizo T, editors. Targeting chitin-containing organisms. Singapore: Springer Singapore; 2019. p. 5-18.

11. Ogawa Y, Lee CM, Nishiyama Y, Kim SH. Absence of sum frequency generation in support of rrthorhombic symmetry of a-chitin. Macromolecules. 2016;49:7025-31.

12. Zeng J, He Y, Li S, Wang Y. Chitin whiskers: an overview. Biomacromol. 2012:13:1-11.

13. Rinaudo M. Chitin and chitosan: properties and applications. Prog Polym Sci. 2006;31:603-32.

14. Morin-Crini N, Lichtfouse E, Torri G, Crini G. Applications of chitosan in food, pharmaceuticals, medicine, cosmetics, agriculture, textiles, pulp and paper, biotechnology, and environmental chemistry. Environ Chem Lett. 2019:17:1667-92.

15. Rolandi M, Rolandi R. Self-assembled chitin nanofibers and applications. Adv Coll Interface Sci. 2014:207:216-22.
16. Boyles MSP, Kristl T, Andosch A, Zimmermann M, Tran N, Casals E, Himly M, Puntes V, Huber CG, Lütz-Meindl U, Duschl A. Chitosan functionalisation of gold nanoparticles encourages particle uptake and induces cytotoxicity and pro-inflammatory conditions in phagocytic cells, as well as enhancing particle interactions with serum components. Journal of Nanobiotechnology. 2015;13:84.

17. Freire PLL, Albuquerque AJR, Farias IAP, da Silva TG, Aguiar JS, Galembeck A, Flores MAP, Sampaio FC, Stamford TCM, Rosenblatt A. Antimicrobial and cytotoxicity evaluation of colloidal chitosan silver nanoparticles - fluoride nanocomposites. Int J Biol Macromol. 2016;93:896-903.

18. Loutfy SA, Alam El-Din HM, Elberry MH, Allam NG, Hasanin MTM, Abdellah AM. Synthesis, characterization and cytotoxic evaluation of chitosan nanoparticles: in vitro liver cancer model. Adv Nat Sci NanoSci NanoTechnol. 2016;7:035008.

19. Shamshina JL, Oldham T, Rogers RD. Applications of chitin in agriculture. In: Crini G, Lichtfouse E, editors. Sustainable agriculture reviews 36: chitin and chitosan: applications in food, agriculture, pharmacy, medicine and wastewater treatment. Cham: Springer International Publishing; 2019. p. 125-46.

20. Kheiri A, Moosawi Jorf SA, Malihipour A, Saremi H, Nikkhah M. Application of chitosan and chitosan nanoparticles for the control of Fusarium head blight of wheat (Fusarium graminearum) in vitro and greenhouse. Int J Biol Macromol. 2016;93:1261-72.

21. Samarah NH, Wang H, Welbaum GE. Pepper (Capsicum annuum) seed germination and vigour following nanochitin, chitosan or hydropriming treatments. Seed Science Technology. 2016;44:609-23.

22. Zhang X, Li K, Xing R, Liu S, Li P. Metabolite profiling of wheat seedlings induced by chitosan: Revelation of the enhanced carbon and nitrogen metabolism. Front Plant Sci. 2017;2017:8.

23. Djiwanti SR, Kaushik S. Nanopesticide: future application of nanomaterials in plant protection. In: Prasad R, editor. Nanotechnology in the life sciences. Cham: Springer Nature Switzerland; 2019. p. 255-98.

24. Murugan K, Anitha J, Dinesh D, Suresh U, Rajaganesh R, Chandramohan B, Subramaniam J, Paulpandi M, Vadivalagan C, Amuthavalli P, et al. Fabrication of nano-mosquitocides using chitosan from crab shells: Impact on non-target organisms in the aquatic environment. Ecotoxicol Environ Saf. 2016;132:318-28.

25. Badawy MEI, El-Aswad AF. Insecticidal activity of chitosans of different molecular weights and chitosan-metal complexes against cotton leafworm Spodoptera littoralis and oleander Aphid Aphis nerii. Plant Prot Sci. 2012;48:131-41.

26. Linden JC, Stoner RJ, Knutson KW, Gardner-Hughes CA. Organic disease control elicitors. Agro Food Industry Hi-Tech. 2000;11:32-4.

27. Aranaz I, Mengibar M, Harris R, Panos I, Miralles B, Acosta N, Galed G, Heras A. Functional characterization of chitin and chitosan. Curr Chem Biol. 2009;3:203-30.

28. Dasan YK, Bhat AH, Khan I. Nanocellulose and nanochitin for water remediation by adsorption of heavy metals. In: Ajay KM, Hussain CM, Mishra SB, editors. Nanomaterials for water remediation. 2nd ed. Berlin: De Gruyter; 2020. p. 1-18.

29. Malerba M, Cerana R. Recent applications of chitin- and chitosan-based polymers in plants. Polymers. 2019;11:839.

30. Wu J, Cheng X, Li Y, Yang G. Constructing biodegradable nanochitincontained chitosan hydrogel beads for fast and efficient removal of Cu(II) from aqueous solution. Carbohyd Polym. 2019;211:152-60.

31. Cheng Y, Wang Y, Han Y, Li D, Zhang Z, Zhu X, Tan J, Wang H. The stimulatory effects of nanochitin whisker on carbon and nitrogen metabolism and on the enhancement of grain yield and crude protein of winter wheat. Molecules. 2019;24:1752.

32. Xue W, Han Y, Tan J, Wang Y, Wang G, Wang H. Effects of nanochitin on enhancement of grain yield and quality of winter wheat. J Agric Food Chem. 2018;66:6637-45.

33. Parada RY, Egusa M, Aklog YF, Miura C, Ifuku S, Kaminaka H. Optimization of nanofibrillation degree of chitin for induction of plant disease resistance: Elicitor activity and systemic resistance induced by chitin nanofiber in cabbage and strawberry. Int J Biol Macromol. 2018;118:2185-92.

34. Jung W-J, Park R-D. Bioproduction of chitooligosaccharides: Present and perspectives. Mar Drugs. 2014;12:5328-56. 
35. Goodrich JD, Winter WT. a-chitin nanocrystals prepared from shrimp shells and their specific surface area measurement. Biomacromol. 2007;8:252-7.

36. Bajaj M, Winter J, Gallert C. Effect of deproteination and deacetylation conditions on viscosity of chitin and chitosan extracted from Crangon crangon shrimp waste. Biochem Eng J. 2011;56:51-62.

37. Marchessault RH, Morehead FF, Walter NM. Liquid crystal systems from fibrillar polysaccharides. Nature. 1959;184:632-3.

38. Zhou H, Tan Y, Lv S, Liu J, Muriel Mundo JL, Bai L, Rojas OJ, McClements DJ. Nanochitin-stabilized pickering emulsions: Influence of nanochitin on lipid digestibility and vitamin bioaccessibility. Food Hydrocolloids. 2020;106:105878

39. Mincea M, Negrulescu A, Ostafe V. Preparation, modification, and application of chitin nanowhiskers: A review. Rev Adv Mater Sci. 2012;30:225-42.

40. Zhou Y, Jing M, Levy A, Wang H, Jiang S, Dou D. Molecular mechanism of nanochitin whisker elicits plant resistance against Phytophthora and the receptors in plants. Int J Biol Macromol. 2020;165:2660-7.

41. Zhou $Y$, Jiang $S$, Jiao $Y$, Wang $H$. Synergistic effects of nanochitin on inhibition of tobacco root rot disease. Int J Biol Macromol. 2017;99:205-12.

42. Liang R, Li X, Yuan W, Jin S, Hou S, Wang M, Wang H. Antifungal activity of nanochitin whisker against crown rot diseases of wheat. J Agric Food Chem. 2018;66:9907-13.

43. Li Z, Su L, Wang H, An S, Yin X. Physicochemical and biological properties of nanochitin-abamectin conjugate for Noctuidae insect pest control. J Nanopart Res. 2020;22:286.

44. Li Z, Wang H, An S, Yin X. Toxicity and control efficacy of nanochitin to wheat aphids (In Chinese with English abstract). J Henan Agric Univ. 2016;50:635-40.

45. Bai L, Huan S, Xiang W, Liu L, Yang Y, Nugroho RWN, Fan Y, Rojas OJ. Selfassembled networks of short and long chitin nanoparticles for oil/water interfacial superstabilization. ACS Sust Chem Eng. 2019;7:6497-511.

46. Larbi F, García A, del Valle LJ, Hamou A, Puiggalí J, Belgacem N, Bras J. Comparison of nanocrystals and nanofibers produced from shrimp shell a-chitin: From energy production to material cytotoxicity and pickering emulsion properties. Carbohyd Polym. 2018;196:385-97.

47. Zhao X, Wan Q, Fu X, Meng X, Ou X, Zhong R, Zhou Q, Liu M. Toxicity evaluation of one-dimensional nanoparticles using\&nbsp;Caenorhabditis elegans: a comparative study of halloysite nanotubes and chitin nanocrystals. ACS Sust Chem Eng. 2019;7:18965-75.

48. Zhao J, Wu J. Preparation and characterization of the fluorescent chitosan nanoparticle probe. Chin J Anal Chem. 2006;34:1555-9.

49. Malvern R. Dynamic light scatering, common terms defined. Inform White Paper. 2011;2:1-6.

50. Danaei M, Dehghankhold M, Ataei S, Hasanzadeh Davarani F, Javanmard R, Dokhani A, Khorasani S, Mozafari MR. Impact of particle size and polydispersity index on the clinical applications of lipidic nanocarrier systems. Pharmaceutics. 2018;10:57.
51. Zhang P, Zhang X, Zhao Y, Wei Y, Mu W, Liu F. Effects of imidacloprid and clothianidin seed treatments on wheat aphids and their natural enemies on winter wheat. Pest Manag Sci. 2016;72:1141-9.

52. Zuo Y, Wang K, Zhang M, Peng X, Piñero JC, Chen M. Regional susceptibilities of Rhopalosiphum padi (Hemiptera: Aphididae) to ten insecticides. Florida Entomologist. 2016;99:269-75.

53. Zhang L, Lu H, Guo K, Yao S, Cui F. Insecticide resistance status and detoxification enzymes of wheat aphidsSitobion avenaeandRhopalosiphum padi. Science China Life Sciences. 2017;60:927-30.

54. Wang K, Zhang M, Huang Y, Yang Z, Su S, Chen M. Characterisation of imidacloprid resistance in the bird cherry-oat aphid, Rhopalosiphum padi. Pest Manag Sci. 2018;74:1457-65.

55. Yu X-Q, Zhang S, Song S-E, Zhu Q-R, Xie C-F, Ji J, Gao X-W. Resistance of wheat aphids to six insecticides and assessment of their field efficacy (in Chinese with Englist abstract). Acta Entomol Sinica. 2016;59:1206-12.

56. Kumar S, Nehra M, Dilbaghi N, Marrazza G, Hassan AA, Kim K-H. Nanobased smart pesticide formulations: Emerging opportunities for agriculture. J Controlled Release. 2019;294:131-53.

57. US/EPA. Chitin; Poly-N-acetyl-D-glucosamine fact sheet (128991). 2001.

58. US/EPA. Chitin/chitosan, farnesol/nerolidol and nosema locustae final registration review decision; Notice of availability. Fed Reg. 2008;73:79096-7.

59. US/FDA. Shrimp-derived chitosan. GRAS Notice (GRN) No. 443. 2013.

60. Yang $X$, Liu J, Pei Y, Zheng $X$, Tang K. Recent progress in preparation and application of nano-chitin materials. Energy Environmental Materials. 2020;0:1-14.

61. Fothergill SM, Joyce C, Xie F. Metal enhanced fluorescence biosensing: from ultra-violet towards second near-infrared window. Nanoscale. 2018;10:20914-29.

62. Hassan UA, Hussein MZ, Alitheen NB, Yahya Ariff SA, Masarudin MJ. In vitro cellular localization and efficient accumulation of fluorescently tagged biomaterials from monodispersed chitosan nanoparticles for elucidation of controlled release pathways for drug delivery systems. Int J Nanomed. 2018;13:5075-95.

63. Morganti P, Febo P, Cardillo M, Donnarumma G, Baroni A. Chitin nanofibril and nanolignin: natural polymers of biomedical interest. J Clin Cosm Dermatol. 2017;1:103530992.

64. Azuma K, Ifuku S, Osaki T, Okamoto Y, Minami S. Preparation and biomedical applications of chitin and chitosan nanofibers. J Biomed Nanotechnol. 2014;10:2891-920

65. Solairaj D, Rameshthangam P, Arunachalam G. Anticancer activity of silver and copper embedded chitin nanocomposites against human breast cancer (MCF-7) cells. Int J Biol Macromol. 2017;105:608-19.

\section{Publisher's note}

Springer Nature remains neutral with regard to jurisdictional claims in published maps and institutional affiliations. 